\title{
Power Control at Grid Connected Converters and Analytical Solution of Steady States
}

\author{
Viktor Valouch, ${ }^{1}$ Jiří Škramlík, ${ }^{1}$ Zdeněk Muller, ${ }^{2}$ Jan Švec, ${ }^{2}$ and Josef Tlustý ${ }^{2}$ \\ ${ }^{1}$ Institute of Thermomechanics, Academy of Sciences of the Czech Republic, 18200 Prague, Czech Republic \\ ${ }^{2}$ Department of Electric Power Engineering, Faculty of Electrical Engineering, CTU in Prague, 16000 Prague, Czech Republic \\ Correspondence should be addressed to Zdeněk Muller; zdenek.muller@fel.cvut.cz
}

Received 1 July 2015; Accepted 2 September 2015

Academic Editor: Bin Jiang

Copyright (c) 2015 Viktor Valouch et al. This is an open access article distributed under the Creative Commons Attribution License, which permits unrestricted use, distribution, and reproduction in any medium, provided the original work is properly cited.

\begin{abstract}
The paper presents a power control technique at grid connected converters under unbalanced voltage conditions. The current positive and negative sequences during grid voltage sags are controlled to ensure a proper exchange of active and reactive powers without power ripples. An analytical solution in a closed form of the B6 and B4 converters working with an optimized half a period switching symmetry is presented. The analytical solution may be applied for the converters connected to highly unbalanced grids and for different grid filter topologies.
\end{abstract}

\section{Introduction}

Today, converters connected to the grid must cope with some grid disturbances due to low power DSs (Distributed Sources) connected via these converters to the grid $[1,2]$. Voltage sags are the most frequent type of these grid disturbances. The presence of negative-sequence components in the voltage during these sags causes a negative-sequence current and possible ripple in the power injected to the grid.

Several power control strategies have been developed to ensure a proper exchange of active and reactive powers with the grid without active and reactive power ripple, with a low total harmonic distortion of grid currents, and/or minimum grid current peaks during voltage sags [3-7].

In [4] several possible current control strategies were investigated and compared. It was declared that it is possible to get both zero active and zero reactive power fluctuations only if we accept the currents distorted by harmonics. Although another option referred in [4] exhibited there exhibited harmonic-free converter currents, either the instantaneous active or reactive power was fluctuating.

Two instantaneous reactive power concepts were mostly used in the current control schemes proposed, analyzed, and compared in these references. The first one is the generalized instantaneous reactive power (IRP) theory based formulation of the instantaneous reactive power as the modulus of the cross product of the voltage and current vector [8]. The second one defines the instantaneous reactive power by the dot product of the voltage vector orthogonal to the original voltage vector and the current vector.

Some research efforts have been also made to develop power converters with reduced losses and costs $[9,10]$. Among these circuits, the three-phase converter with only two inverter legs (B4), contrary to a conventional converter with three legs (B6), is a solution. In [11], an application of the B4 topology has been proposed for a renewable-energy-based microgrid interconnection. The B4 topology was applied deliberately in an effort to reduce the cost of the inverter.

An original concept of the instantaneous active and reactive powers expressed in the phase coordinates was introduced in [12] to improve the performance criteria of a shunt active power filter. The same principle was applied in [13] to find four current reference components for a PWM rectifier providing ripple-free dc output voltage under unbalanced conditions. Being inspired by that, we will present here a control strategy of the current vector $\mathbf{i}$ providing the precise instantaneous active and reactive power control and harmonic-free converter currents at the same time.

An analytical solution in a closed form of the B6 as well as B4 grid connected converter working with a half a period 
switching symmetry is also presented in the contribution. The proposed optimized switching strategy is characterized by a good current as well as instantaneous power tracking capability and by minimum switching frequency too. In the examples presented, the converter is connected to the threephase unbalanced grid via either an $L$ or an $L C L$ filter.

\section{Reference Current for Instantaneous Power Control}

Let the definition of the instantaneous active $p$ and reactive (nonactive) $q$ power be as follows:

$$
\mathbf{s}=p+j q=\frac{3}{2}\left[\operatorname{Re}\left\{\mathbf{v i}^{*}\right\}+j \operatorname{Re}\left\{\mathbf{v}\left(t-\frac{T_{1}}{4}\right) \mathbf{i}^{*}\right\}\right],
$$

where $\mathbf{s}$ is called the complex power, $\mathbf{v}, \mathbf{i}$ stand for the voltage and current vectors in the SRF ${ }^{\mathrm{P}}$ (Synchronous Reference Frame rotating in the positive direction by the synchronous speed $\left.\omega_{1}=2 \pi / T_{1}\right), j$ is the imaginary unit, and $T_{1}$ is the fundamental period. The coefficient $3 / 2$ appears here because such a transformation of the voltages and currents between the $a, b, c$ and SRF systems conserves voltage and current magnitudes. The complex conjugate vectors are marked by the symbol of the asterisk $(*)$.

Contrary to usage of the formula for the complex power defined by the IRP theory, solution of complex equation (1) for getting the current vector $\mathbf{i}$ seems to be a problem here.

But if we denote $\mathbf{v}^{\prime}=\mathbf{v}\left(t-T_{1} / 4\right)$, we can write

$$
p \mathbf{v}^{\prime}-q \mathbf{v}=\frac{3}{4}\left(\mathbf{v}^{*} \mathbf{v}^{\prime}-\mathbf{v}^{\prime *} \mathbf{v}\right) \mathbf{i}=-\frac{3}{2} j \operatorname{Im}\left\{\mathbf{v}^{\prime *} \mathbf{v}\right\} \mathbf{i} .
$$

In case of an unbalanced voltage grid and considering that the current generated by the converter is also unbalanced, we can express the voltage and current vectors $\mathbf{v}, \mathbf{i}$ as follows:

$$
\begin{aligned}
\mathbf{v} & =\mathbf{v}^{\mathrm{p}}+\mathbf{v}^{\mathrm{n}} e^{-j 2 \omega_{1} t}, \\
\mathbf{v}^{\prime} & =-j\left(\mathbf{v}^{\mathrm{p}}-\mathbf{v}^{\mathrm{n}} e^{-j 2 \omega_{1} t}\right), \\
\mathbf{i} & =\mathbf{i}^{\mathrm{p}}+\mathbf{i}^{\mathrm{n}} e^{-j 2 \omega_{1} t},
\end{aligned}
$$

where the superscripts $\mathrm{p}$ and $\mathrm{n}$ refer to the positive and negative sequence of the voltage and current vector that are constants in steady states in the $\mathrm{SRF}^{\mathrm{P}}$ and $\mathrm{SRF}^{\mathrm{n}}$ (SRF rotating in the negative direction), respectively. We suppose here for the following analysis that the voltages as well as currents are harmonic-free. The current vectors $\mathbf{i}^{\mathrm{p}}, \mathbf{i}^{\mathrm{n}}$ will be the reference vectors calculated to fulfill demanded objectives; the asterisks used usually to mark the reference variables will be omitted here to avoid a mistake because the same symbol is used for the complex conjugate vectors.

If the following relations (4), (5) are considered,

$$
\begin{array}{r}
\mathbf{v}^{\prime *} \mathbf{v}=j\left[v^{\mathrm{p}^{2}}-v^{\mathrm{n}^{2}}+j 2 \operatorname{Im}\left\{\mathbf{v}^{\mathrm{p} *} \mathbf{v}^{\mathrm{n}} e^{-j 2 \omega_{1} t}\right\}\right], \\
\operatorname{Im}\left\{\mathbf{v}^{\prime *} \mathbf{v}\right\}=v^{\mathrm{p}^{2}}-v^{\mathrm{n}^{2}}=v^{\mathrm{p}^{2}}\left(1-n^{2}\right), \quad n=\frac{\left|\mathbf{v}^{\mathrm{n}}\right|}{\left|\mathbf{v}^{\mathrm{p}}\right|},
\end{array}
$$

where $n$ is the unbalance factor, the final formula for the converter reference current (6) may be formulated on the basis of (2):

$$
\begin{aligned}
\mathbf{i} & =\frac{2}{3} \frac{j}{\operatorname{Im}\left\{\mathbf{v}^{\prime *} \mathbf{v}\right\}}\left(p \mathbf{v}^{\prime}-q \mathbf{v}\right)=\frac{2}{3} \frac{j}{v \mathrm{p}^{2}-v^{\mathrm{n}^{2}}}\left(p \mathbf{v}^{\prime}-q \mathbf{v}\right) \\
& =\frac{2}{3} \frac{j}{v \mathrm{p}^{2}\left(1-n^{2}\right)}\left(p \mathbf{v}^{\prime}-q \mathbf{v}\right) .
\end{aligned}
$$

The expression of (6) in $d, q$ axes of the $\mathrm{SRF}^{\mathrm{p}}$ is provided in Appendix C.

It is well known that using the IRP theory for an unbalanced voltage $\mathbf{v}$, the current vector $\mathbf{i}$ is also unbalanced and nonsinusoidal [14]. But it may be deduced from (6) that here although the grid current $\mathbf{i}$ remains unsymmetrical due to the negative-sequence component of $\mathbf{v}$, no harmonic components are present in it. Nevertheless, if the grid voltage contains a certain harmonic component $\mathbf{v}_{\mathrm{h}}$, the grid phase currents are nonsinusoidal as well and the components of the related complex power $\mathbf{s}$ contain a harmonic signal.

Let us examine what the time responses of the instantaneous powers $p, q$ will be like if the reference current (6) is used and some constant powers $P$ and $Q$ are required.

Substituting (6) into (1) and considering (5) we obtain

$$
\begin{aligned}
p & =\frac{3}{2} \operatorname{Re}\left\{\mathbf{v i}^{*}\right\}=\operatorname{Re}\left\{\mathbf{v} \frac{j}{v^{\mathrm{p}^{2}}-v^{\mathrm{n}^{2}}}\left(Q \mathbf{v}^{*}-P \mathbf{v}^{\prime *}\right)\right\} \\
& =\frac{1}{v^{\mathrm{p}^{2}}-v^{\mathrm{n}^{2}}} \operatorname{Re}\left\{j Q v^{2}-j P \mathbf{v} \mathbf{v}^{\prime *}\right\}=P, \\
q & =\frac{3}{2} \operatorname{Re}\left\{\mathbf{v}^{\prime} \mathbf{i}^{*}\right\}=\operatorname{Re}\left\{\mathbf{v}^{\prime} \frac{j}{v^{\mathrm{p}^{2}}-v^{\mathrm{n}^{2}}}\left(Q \mathbf{v}^{*}-P \mathbf{v}^{\prime *}\right)\right\} \\
& =\frac{1}{v^{\mathrm{p}^{2}}-v^{\mathrm{n}^{2}}} \operatorname{Re}\left\{j Q \mathbf{v}^{\prime} \mathbf{v}^{*}-j P v^{\prime 2}\right\}=Q .
\end{aligned}
$$

So the advantage of this method is that no undesirable active and reactive pulsating power components $\widetilde{p}$ and $\tilde{q}$ are appearing, which may be the case of some strategies published so far. We will call this power control, in compliance with the term used in [4], as the Instantaneous ActiveReactive Control (IARC).

The BPSC (Balanced Positive Sequence Control) strategy [4] will be tested in the following simulation as well but only to show a character of possible instantaneous active and reactive power responses.

\section{Converter Configuration and Space-Vector Modulation for B6 and B4 Connection}

Eight possible voltage vectors for B6 connection are shown in Figure 1. Six of them have the same magnitude $2 V_{\mathrm{dc}} / 3$, while the remaining two are zero vectors. A switching vector $\left(S_{a}, S_{b}, S_{c}\right)$ denotes the inverter switching states, in which $S_{i}=$ $1(i=a, b, c)$ if the upper leg switch is on and $S_{i}=0$ if the upper leg switch is off. The vector $\mathbf{v}_{\mathrm{COAV}}$ is a reference average ac-terminal voltage vector that should be generated by a proper PWM strategy. 


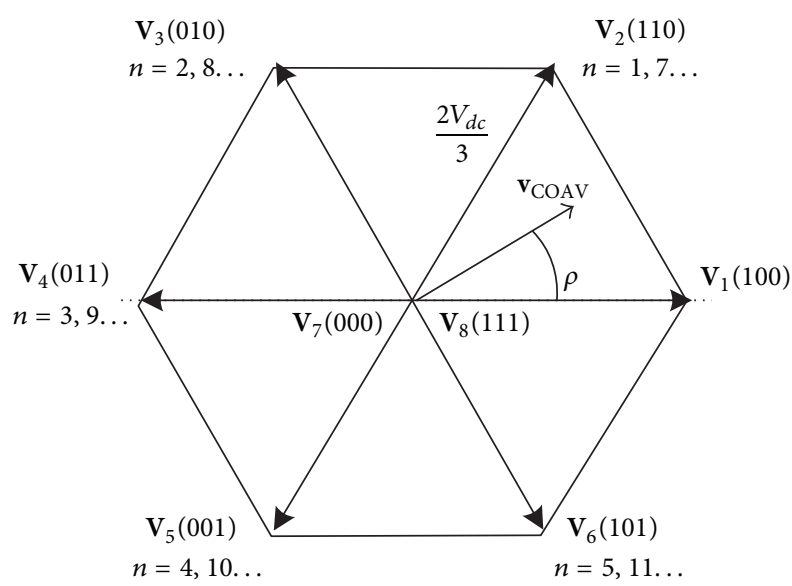

Figure 1: Voltage vectors for B6 connection.

The sixfold switching symmetry assumes that all switching times valid for one-sixth of the output period are the same also in the remaining sixths of this period. The presence of negative-sequence components in the grid voltage and current results in that the voltage generated by the converter contains also a negative-sequence component, though. Thus, the converter voltage vector draws an ellipsoid with different time intervals of individual sixth of the fundamental cycle with different numbers of sampling periods.

To overcome this obstacle, we will formulate here a closed-form solution using a proposed concept of optimized half a period switching strategy.

We express time in terms of the sector number $n$ and per unit time variable $\varepsilon$ as

$$
t=\frac{(n+\varepsilon) T_{1}}{2}=(n+\varepsilon) T \quad n=0,1,2, \ldots 0 \leq \varepsilon \leq 1,
$$

where $T_{1}$ is a fundamental period and $T$ is time of periodicity of a space-vector modulation called a sector period:

$$
T=\frac{T_{1}}{2} .
$$

Let every half of the fundamental period of the length $T_{1}$ be divided into $N_{1}$ segments with a sampling period

$$
\Delta T=\frac{T_{1}}{2 N_{1}}=\frac{T}{N_{1}} .
$$

An optimum PWM modulation may be attained if the deviation of the current vector from a reference vector is as small as possible.

The condition is met if only three voltage vectors are used and the sampling period, wherein the average voltage vector becomes equal to the reference vector, consists of three successive switching states only [15].

To obtain a minimum switching frequency of the converter needs that the transition from one switching state to the next one is performed by switching only one converter leg.
So, the conditions mentioned above are met if only three voltage vectors are switched within two sampling periods $2 \Delta T$ in the sequence

$$
\begin{aligned}
& \mathbf{V}_{7}(000), \mathbf{V}_{1}(100), \mathbf{V}_{2}(110), \mathbf{V}_{8}(111), \\
& \mathbf{V}_{8}(111), \mathbf{V}_{2}(110), \mathbf{V}_{1}(100), \mathbf{V}_{7}(000)
\end{aligned}
$$

and so forth, in the first sixth of the fundamental period $\left(n_{s}=0\right)$ where the index $n_{s}=0,1,2$ for the angle $\rho$ inside the 1st, $2 \mathrm{nd}$, and 3 rd sixth of every half a fundamental period $T_{1}$, respectively.

Thus the following two equations should be satisfied in order that three applied voltage vectors may generate the demanded average converter voltage vector $\mathbf{v}_{\mathrm{COAV}}$ :

$$
\begin{aligned}
\mathbf{v}_{\mathrm{COAV}} e^{j \rho} \Delta T & =\frac{2 V_{\mathrm{dc}}}{3} \Delta T_{1}+\frac{2 V_{\mathrm{dc}}}{3} \Delta T_{2} e^{j \pi / 3}, \\
\Delta T & =\Delta T_{1}+\Delta T_{2}+\Delta T_{3},
\end{aligned}
$$

where $\rho$ is the angle to the beginning boundary of the sector (to the real axis here) and $\Delta T_{1}, \Delta T_{2}$, and $\Delta T_{3}$ are the time portions allocated to the vectors $\mathbf{V}_{1}(100), \mathbf{V}_{2}(110)$, and $\mathbf{V}_{7}(000)$ (or $\mathbf{V}_{8}(111)$ ). Solving (12) we obtain the switching time intervals $\Delta \varepsilon_{1}=\Delta T_{1} / T, \Delta \varepsilon_{2}=\Delta T_{2} / T$, and $\Delta \varepsilon_{3}=\Delta T_{3} / T$ (in p.u. time related to the time interval $T$ of half a period).

The PWM strategy can be, according to (8)-(12), described as follows:

$$
\mathbf{v}_{\mathrm{CO}}\left(n, n_{s}, \varepsilon\right)=\sum_{k=1}^{3 N_{1}} 2 \frac{V_{\mathrm{dc}}}{3} e^{j \pi n} e^{j \pi\left(n_{s} / 3\right)} f(\varepsilon, k) e^{j(\pi / 3) \alpha(k)} .
$$

Three adjacent vectors used in the SVM strategy are characterized by

$$
\alpha(k)= \begin{cases}(k \text { modulo } 3)-1 & \text { for } k \text { odd }, \\ 3-(k \text { modulo } 3) & \text { for } k \text { even, }\end{cases}
$$

while the switching functions $f(\varepsilon, k)$ describing the switching patterns are defined as follows:

$$
f(\varepsilon, k)= \begin{cases}1 & \text { if } \varepsilon_{A k} \leq \varepsilon \leq \varepsilon_{B k}, \\ 0 & \text { else }\end{cases}
$$

where $\varepsilon_{A k}, \varepsilon_{B k}$ are the start point setting time and end point setting time, respectively, of the $k$ th voltage vector. The switching time intervals $\varepsilon_{B k}-\varepsilon_{A k}=\Delta \varepsilon_{k}$ (p.u.) are determined by solving (12).

A circuit diagram of the $\mathrm{B} 4$ converter resulting from the complete B6 connection is shown in Figure 2. The scheme employs four switches and diodes to generate output voltage. The phase $a$ is directly connected to the midpoint of the split dc capacitor $C_{\mathrm{dc}}$. The $L C L$ grid filter is used to achieve line current filtering and to obtain dc link voltage boost operation.

Four different voltage vectors in the $\alpha \beta$ plane, resulting from all possible combinations of the conduction states of the power switches, are shown in Figure 3. These vectors are $\pi / 2$ away from each other. Vectors lying on the real axis 


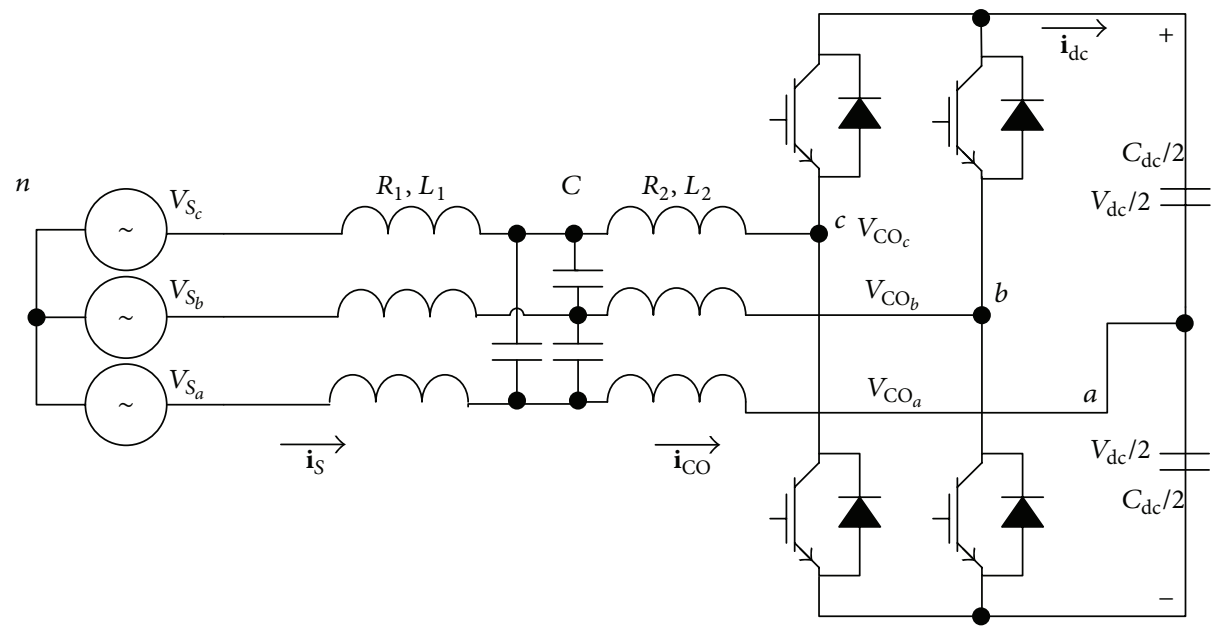

FIGURE 2: B4 converter connected via $L C L$ filter to grid.

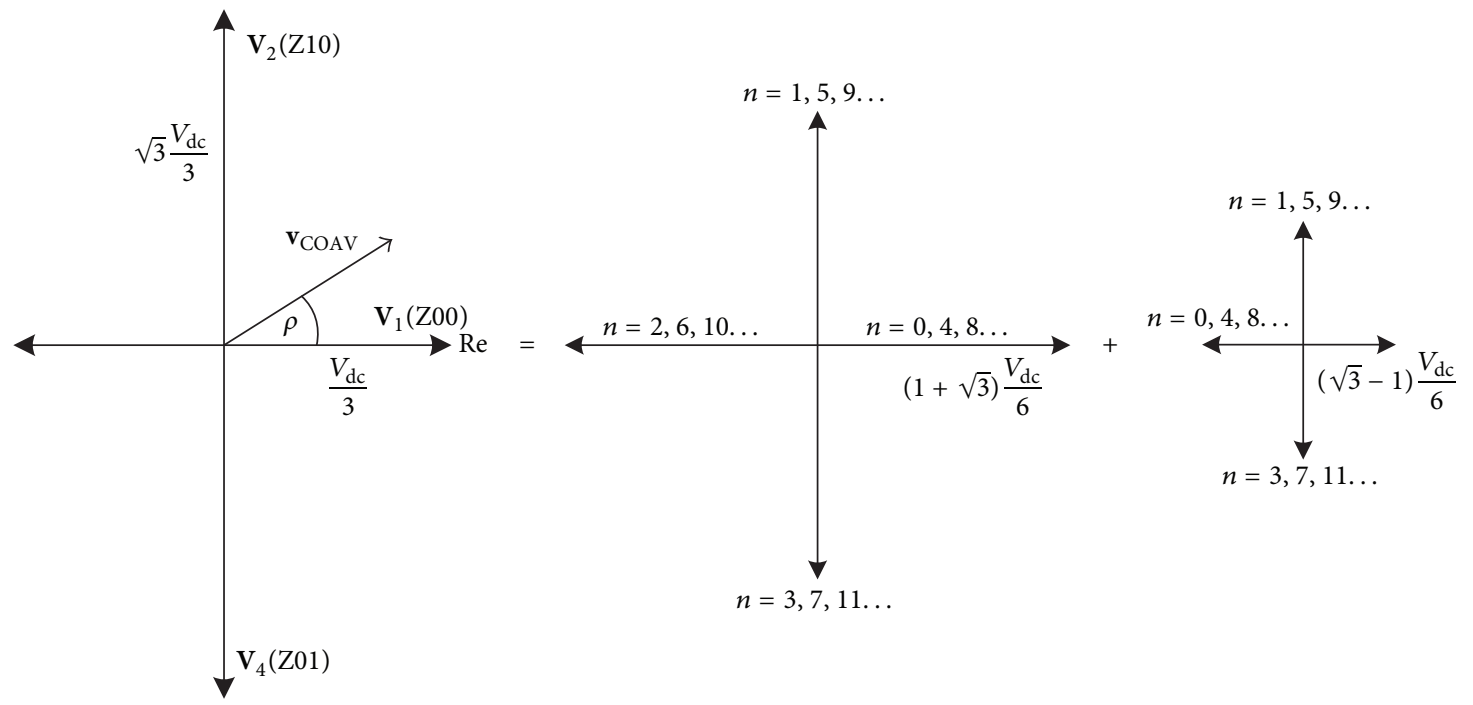

FIgURE 3: Voltage vector decomposition for B4 connection.

have the amplitude of $V_{\mathrm{dc}} / 3$, whereas the vectors lying on the imaginary axis have the amplitude of $V_{\mathrm{dc}} / \sqrt{3}$.

Let the voltage vectors in Figure 3 have the following denotation:

$$
\mathbf{V}_{1}(Z 00), \mathbf{V}_{2}(Z 10), \mathbf{V}_{3}(Z 11), \mathbf{V}_{4}(Z 01)
$$

where $Z$ means zero pole voltage $v_{\mathrm{CO}_{a}}=0$.

Again, like that in (11), only three voltage vectors are switching within two sampling periods $2 \Delta T$ in the sequence

$$
\begin{aligned}
& \mathbf{V}_{1}(Z 00), \mathbf{V}_{2}(Z 10), \mathbf{V}_{3}(Z 11) \\
& \mathbf{V}_{3}(Z 11), \mathbf{V}_{2}(Z 10), \mathbf{V}_{1}(Z 00)
\end{aligned}
$$

and so forth, in the first half a fundamental period $(n=0)$ and in a similar way in the second half a period $(n=1)$.
For example, for the voltage vector $\mathbf{v}_{\mathrm{COAV}}$ lying in the first sector $(n=0)$, Figure 3 , the following two equations should be satisfied in order that the voltage vectors $\mathbf{V}_{1}(Z 00)$, $\mathbf{V}_{2}(Z 10)$, and $\mathbf{V}_{3}(Z 11)$ may generate an average ac-terminal voltage vector matching the vector $\mathbf{v}_{\mathrm{COAV}}$ in the sampling period $\Delta T$ :

$$
\begin{aligned}
\mathbf{v}_{\mathrm{COAV}} e^{j \rho} \Delta T & =\frac{V_{\mathrm{dc}}}{3} \Delta T_{1}+j \frac{\sqrt{3} V_{\mathrm{dc}}}{3} \Delta T_{2}-\frac{V_{\mathrm{dc}}}{3} \Delta T_{3}, \\
\Delta T & =\Delta T_{1}+\Delta T_{2}+\Delta T_{3},
\end{aligned}
$$

where $\rho$ is the angle to the beginning boundary of the sector (to the real axis here) and $\Delta T_{1}, \Delta T_{2}$, and $\Delta T_{3}$ are the time portions allocated to the vectors $\mathbf{V}_{1}(Z 00), \mathbf{V}_{2}(Z 10)$, and $\mathbf{V}_{3}(Z 11)$. Solving (18) we obtain switching time intervals (in p.u. time related to the time interval $T$ of half a period). 
The PWM strategy can be, according to (17) and (18), described as follows:

$$
\begin{aligned}
\mathbf{v}_{\mathrm{CO}}(n, \varepsilon)=\mathbf{v}_{\mathrm{CO}}{ }^{\mathrm{p}}(n, \varepsilon)+\mathbf{v}_{\mathrm{CO}}{ }^{\mathrm{n}}(n, \varepsilon) \\
=\sum_{k=1}^{3 N_{1}}(1+\sqrt{3}) \frac{V_{\mathrm{dc}}}{6} f(\varepsilon, k) e^{j n \pi} e^{j(\pi / 2) \alpha(k)} \\
\quad+\sum_{k=1}^{3 N_{1}}(1-\sqrt{3}) \frac{V_{\mathrm{dc}}}{6} f(\varepsilon, k) e^{-j n \pi} e^{-j(\pi / 2) \alpha(k)},
\end{aligned}
$$

where three adjacent vectors used in the proposed SVM strategy are again characterized by (14) and the switching functions $f(\varepsilon, k)$ by (15).

As we assume that a grid voltage vector contains the positive and negative parts, it may be expressed that

$$
\mathbf{v}_{S}(n, \varepsilon)=V_{S P} e^{j \varphi_{P}} e^{j \omega_{1}(n+\varepsilon) T}+V_{S N} e^{j \varphi_{N}} e^{-j \omega_{1}(n+\varepsilon) T},
$$

where $V_{S P}, \varphi_{P}$ and $V_{S N}, \varphi_{N}$ are, respectively, the amplitude and phase angle of the positive and negative component of the grid voltage vector.

The expressions for the currents $\mathbf{i}_{S}(s), \mathbf{i}_{\mathrm{CO}}(s)$ in the Laplace domain are

$$
\begin{aligned}
\mathbf{i}_{S}(s) & =\frac{B_{S}(s)}{A(s)} \mathbf{v}_{S}(s)-\frac{B_{\mathrm{CO}}(s)}{A(s)} \mathbf{v}_{\mathrm{CO}}(s), \\
\mathbf{i}_{\mathrm{CO}}(s) & =\frac{B_{\mathrm{CO}}(s)}{A(s)} \mathbf{v}_{S}(s)-\frac{B_{\mathrm{SCO}}(s)}{A(s)} \mathbf{v}_{\mathrm{CO}}(s),
\end{aligned}
$$

where $\mathbf{v}_{S}(s), \mathbf{v}_{\mathrm{CO}}(s)$ may be calculated from (20) and either (13) for B6 connection or (19) for B4 connection. The polynomials for the $L C L$ grid filter are given in Appendix A.

The solution of (21) in the time domain contains two terms (see Appendix B for the B6 as well as B4 converter):

$$
\mathbf{i}_{S}(n, \varepsilon)=L^{-1}\left\{\mathbf{i}_{S}(s)\right\}=\mathbf{i}_{S S}(n, \varepsilon)+\mathbf{i}_{S C O}(n, \varepsilon),
$$

where $L^{-1}$ means the inverse Laplace transformation. This step is done by means of the mixed $p-z$ approach [16]. A similar expression can be found for the converter current $\mathbf{i}_{\mathrm{CO}}$.

\section{Results of Simulation and Experiments}

Figures 4-8 show results of simulation in the MATLAB environment where the reference voltage vector $\mathbf{v}_{\mathrm{COref}}=$ $\mathbf{v}_{\mathrm{COAV}}$ is supposed to be determined by a current controller with the reference current vector calculated by (6) for obtaining the active and reactive powers $P=3000 \mathrm{~W}, Q=$ $3000 \mathrm{VA}$, respectively, under an unbalanced $380 / 220 \mathrm{~V}$ grid (with magnitudes of voltage vectors $V_{S P}=210 \mathrm{~V}, V_{S N}=$ $100 \mathrm{~V})$. The converter sampling frequency is $6 \mathrm{kHz}$; that is, the number of switching periods per half a fundamental period $T_{1}=20 \mathrm{~ms}$ is $N_{1}=60$. Thus, according to (11), (17), the converter switching frequency is $3 \mathrm{kHz}$, which can be, for example, recognized also in Figure 6. The $L C L$ filter is used with the following parameters: $R_{1}=R_{2}=0.05 \Omega, L_{1}=L_{2}=$ $0.005 \mathrm{H}, C=10 \mu \mathrm{F}$, and $R=1 \Omega$ (passive dumping resistor

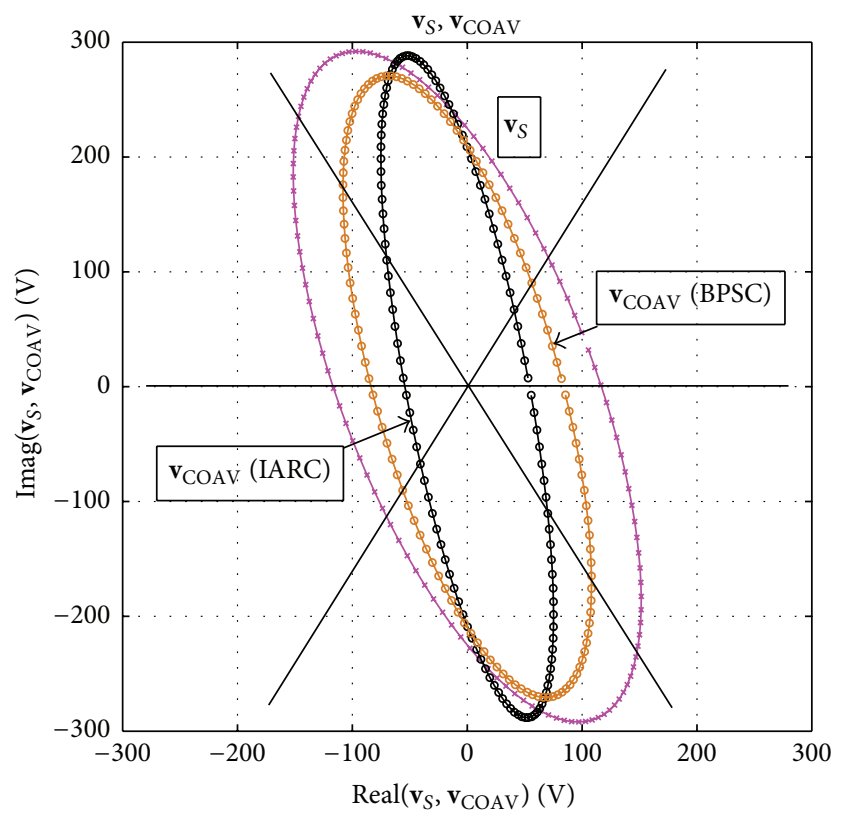

FIgURE 4: Trajectories of grid and converter voltage vectors.

not shown in Figure 2). A few sophisticated procedures have been published till now that took into consideration the main restrictions laid on the $L C L$ filter parameters: $C, L_{1}+L_{2}$ must be limited with respect to an acceptable reactive power and a voltage drop, respectively; $10 f_{1}<f_{\text {REZ }}<f_{\text {SW }} / 2$ (here $500<f_{\mathrm{REZ}}=1000 \mathrm{~Hz}<1500$ ); the value of $R$ is limited by amount of Joule losses produced. In fact, the $L C L$ filter is not exactly optimized here; only its typical acceptable parameters have been selected. Nevertheless, the LCL filter parameters are in concord with the basic rules mentioned above.

Figure 4 shows trajectories of the grid voltage vector $\mathbf{v}_{S}$ and reference converter voltage vectors $\mathbf{v}_{\mathrm{CO} \text { ref }}=\mathbf{v}_{\mathrm{COAV}}$ for the IARC and BPSC strategies. It is evident that the grid voltage unbalanced factor of high value $n_{u}=100 / 210$ results in an unequal distribution of the switching intervals in individual sixths of the fundamental period, for example, 5-47-8 (for the IARC strategy) instead of $20-20-20$ for $N_{1}=60$ in half a fundamental period. Such a case may occur during a singlephase grid voltage dip that belongs among the most common types of sags.

In Figure 5(a), we can see the time responses of the threephase grid currents under unbalanced conditions for the proposed IARC method and the B6 connection. Either the $L C L$ filter or simple $L$ filter with $L=L_{1}+L_{2}$ is used. We can see that the switching frequency for the $L$ filter is much more manifested in the current waveforms than in case of the $L C L$ filter. In Figure 5(b), the current responses for the B4 connection and the $L C L$ filter are presented where either the developed IARC strategy or the BPSC method is applied. In the later case, it results in the balanced responses; however, the penalty for that is fluctuating power components (see Figure 8 later). Comparing Figures 5(a) and 5(b), we see also that the responses for the proposed strategy IARC and the B4 connection are relatively very close to those for the B6 connection. 

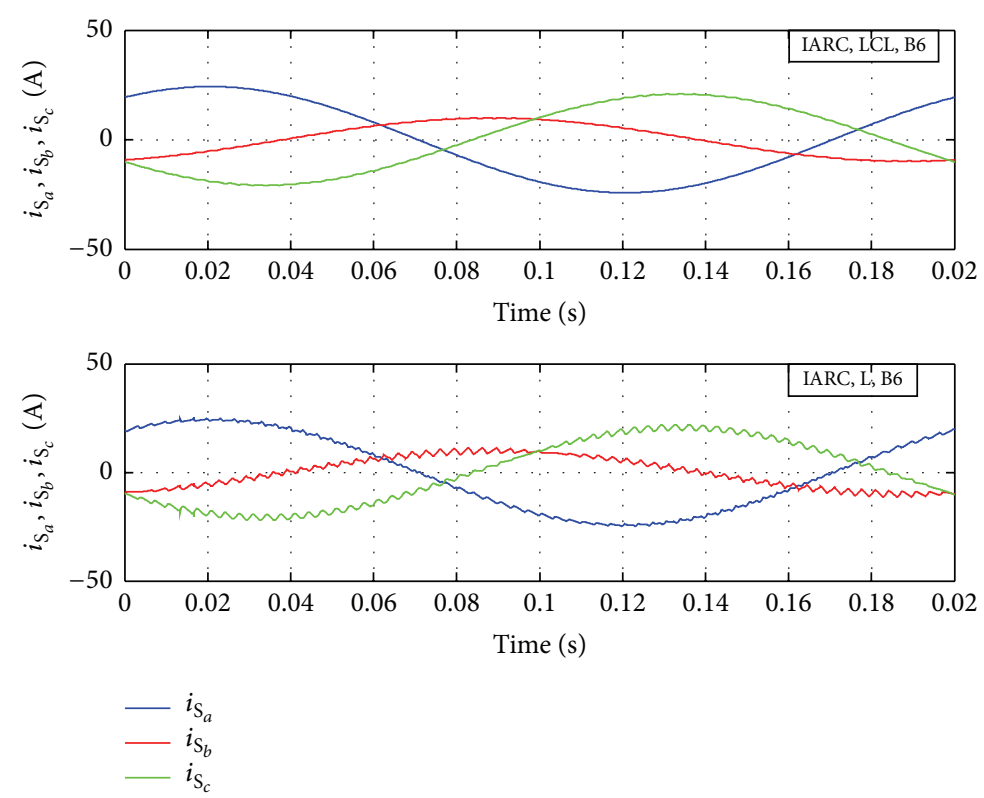

(a)
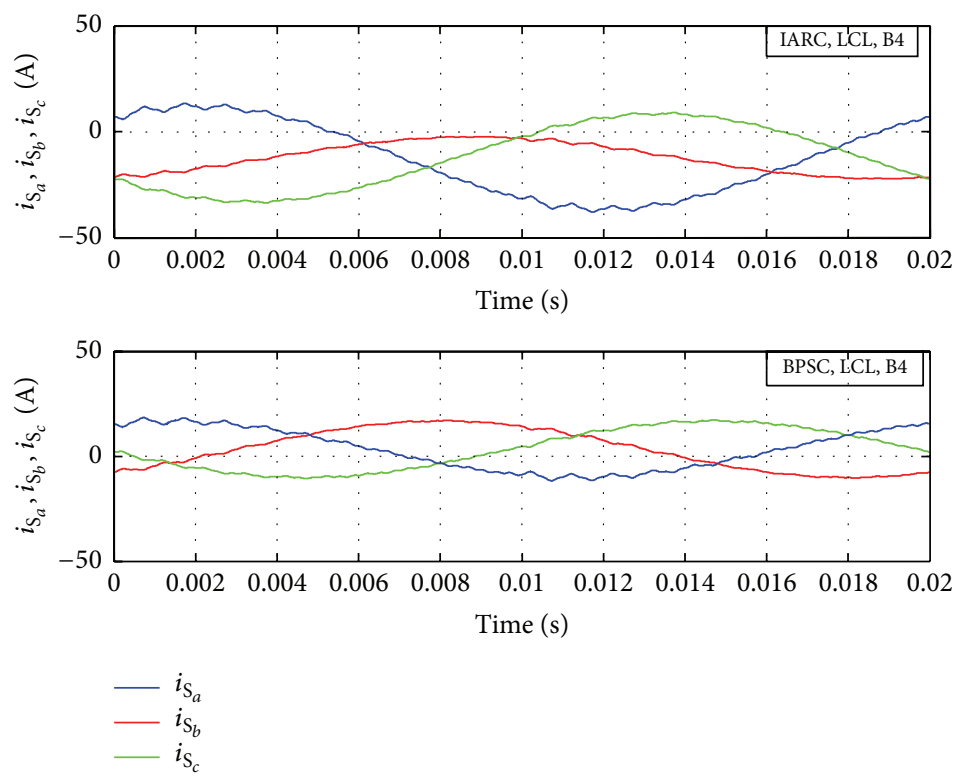

(b)

FIGURE 5: Comparison of trajectories of grid phase currents: (a) IARC, B6 connection, $L C L$ versus $L$ grid filter, (b) B4 connection for $L C L$ filter, IARC versus BPSC method.

Figure 6 compares the harmonic spectra of the current in phase $a$ from Figure 5 for three options of using the IARC method. The known fact is confirmed there, namely, that using the LCL filter brings better harmonic spectrum than using the $L$ filter, especially around the switching frequency $6 \mathrm{kHz}$. Although relatively high current magnitudes around the $L C L$ filter resonance frequency $(1000 \mathrm{~Hz})$ are obtained for the B4 connection, these magnitudes are still small enough which is demonstrated by respective relatively very smooth current responses (Figure 5(b), bottom part). Hence a good quality of the proposed optimized half a period switching symmetry for the B4 connection is confirmed also by that.
Finally, Figures 7 and 8 show responses of the instantaneous active and reactive powers for both the switching strategies compared and two power control methods (IARC, BPSC) used. As for the IARC method, the reference powers $P=3000 \mathrm{~W}, Q=3000 \mathrm{VA}$ are followed with only small error for the $\mathrm{B} 6$ as well as for $\mathrm{B} 4$ connection with respective switching strategies. High pulsating power components with the switching frequency can be seen if only the $L$ grid filter is used, even for the B6 connection, Figure 8 (red responses).

Very high pulsating power components of the frequency $100 \mathrm{~Hz}$ are produced if the BPSC power control method is used, Figure 8 (blue response), which is not desirable in 


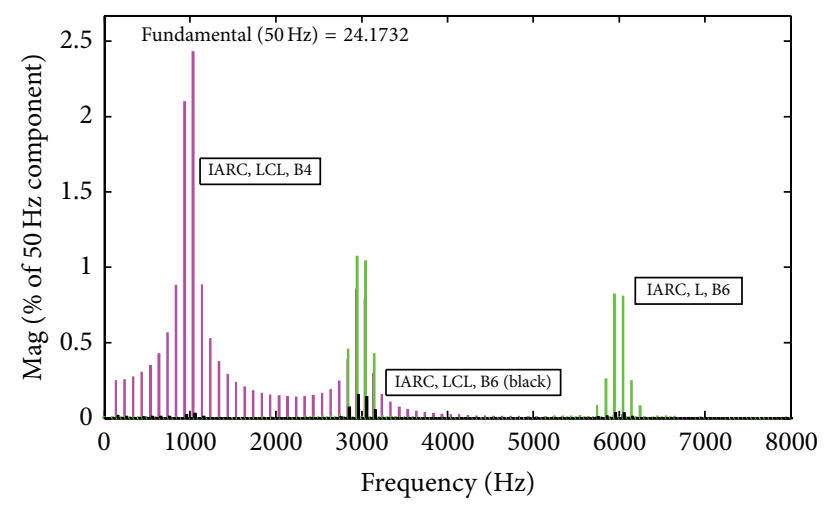

FIGURE 6: Harmonic spectra of the current in phase $a$ from Figure 5 for three options of using IARC method.
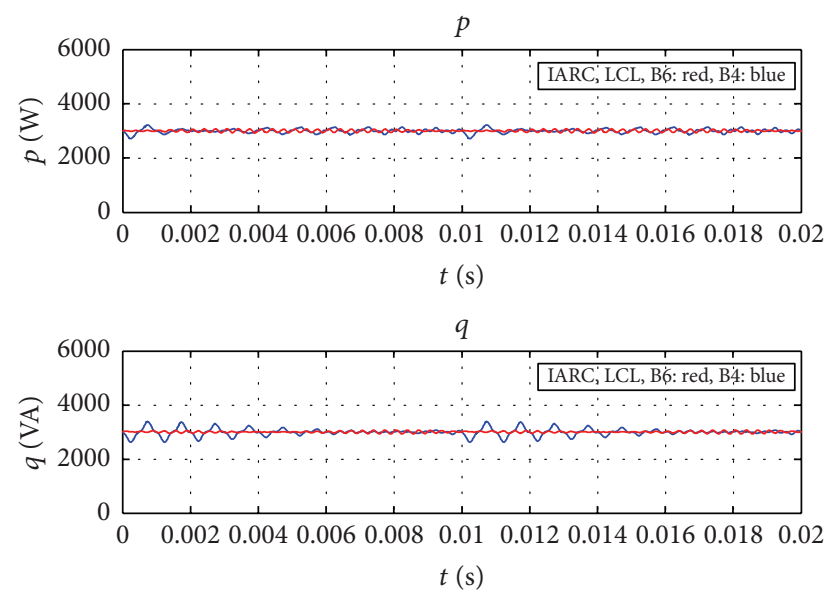

FIgURE 7: Time responses of instantaneous active and reactive powers for IARC method and the proposed optimized half a period symmetry (B4 and B6 connection), LCL grid filter used.

renewable-energy-based grid interconnections realized by such converters. It is a penalty for getting the balanced grid current responses, Figure 5(b), bottom part.

We have also tested both the discussed power control strategies (IARC, BPSC) through experimentations. The experimental system consists of a three-phase inverter in either the B4 or B6 connection and a digital control unit based on the dSPACE control system DS 1103.

Figure 9 shows a simplified block diagram of the control of the converter connected to the grid via the $L C L$ filter. For simplicity, blocks that transform measured phase voltages and currents into the $\mathrm{SRF}^{\mathrm{P}}$ and $\mathrm{SRF}^{\mathrm{n}}$ are not shown. In the figure an option is presented where the converter current $\mathbf{i}_{1}$ is controlled. The structure of the current controller for the $L C L$ grid filter is more complicated than this for the $L$ filter. Two voltages $\mathbf{v}_{C}, \mathbf{v}_{2}$ and two currents $\mathbf{i}_{1}, \mathbf{i}_{2}$ must be measured or estimated. However, the current controller can be simplified [17] neglecting capacitor $C$, especially if it is small. Thus, we do that and performed the controller design like this for the simple $L=L_{1}+L_{2}$ filter. So we measured only $\mathbf{v}=\mathbf{v}_{2}$ and $\mathbf{v}_{\text {CO }}=\mathbf{v}_{1}$ and $\mathbf{i}=\mathbf{i}_{1}$. The PLL (Phase Locked Loop) was used to synchronize the transform blocks and to generate also the signal $\omega$ used in some subblocks of the control structure. The voltage equations for the $L$ filter and the scheme of respective simplified current controller are presented in Appendix C. However, the aim of this contribution is the design and tests of the blocks Current Reference Calculation and SVM (spacevector modulation).

In the block Current Reference Calculation the reference current vector $\mathbf{i}_{r}$ is calculated using (6). The delayed voltage vector $\mathbf{v}^{\prime}=\mathbf{v}\left(t-T_{1} / 4\right)$ is determined storing the values of $\mathbf{v}(t)$ in a buffer and loading them after a quarter $T_{1} / 4$ of the fundamental period up. In the block SVM appropriate three voltage vectors and respective time portions $\Delta T_{1}, \Delta T_{2}$, and $\Delta T_{3}$ allocated to these vectors $\mathbf{V}_{1}, \mathbf{V}_{2}$, and $\mathbf{V}_{3}$ are calculated according to either (11) and (12) for the B6 connection or (17) and (18) for B4 connection.

The whole control scheme, as itself, was implemented in dSPACE control system DS 1103 supported by the MAT$\mathrm{LAB} /$ Simulink environment. So the control scheme may be tuned in Simulink using all its tools and blocks provided and after that translated and transferred into the digital signal processor of the DS 1103 working in the real time with real measured and control variables.

As an illustrative example, a single-phase voltage dip in phase $a$ was realized (type B) by a power system simulator. The $L C L$ filter was used with the following parameters: $R_{1}=$ $R_{2}=0.028 \Omega, L_{1}=L_{2}=0.005 \mathrm{H}, R=2.5 \Omega, C=4.4 \mu \mathrm{F}$, and the sampling frequency was $6 \mathrm{kHz}$. The reference powers were $p^{*}=-300 \mathrm{~W}, q^{*}=300 \mathrm{VA}$ and the voltage unbalance factor was $n=\left|\mathbf{v}^{\mathrm{n}}\right| /\left|\mathbf{v}^{\mathrm{p}}\right|=0.23$.

Figure 10 shows grid voltage and current responses in a steady state for the proposed optimized half a period switching symmetry, B6 converter and the LCL grid filter, captured by the dSPACE control system and processed in MATLAB.

Figure 11 presents the respective trajectories of the instantaneous active and reactive power calculated from measured converter voltages and currents for the proposed IARC strategy and optimized half a period symmetry, the B6 and B4 converter and LCL grid filter.

Figure 12(a) shows the measured converter voltage and current vectors for the IARC method, while Figure 12(b) shows those for the BPSC strategy, both for proposed optimized half a period symmetry, B4 converter and LCL grid filter. We can see that the grid phase currents are in Figure 12(b) relatively good balanced although the voltage system is unsymmetrical, contrary to the current vectors in Figure 12(a) for the IARC strategy.

Figure 13 presents the respective trajectories of the instantaneous active and reactive power calculated from measured converter voltages and currents for this BPSC strategy, the proposed optimized half a period symmetry, B4 converter and LCL grid filter. It is evident that both active and reactive power contain a great pulsating component with the frequency $100 \mathrm{~Hz}$. It is a penalty for getting the balanced grid current responses, Figure 12.

\section{Conclusion}

The paper presents a proposed power control technique at grid connected converters under unbalanced voltage 

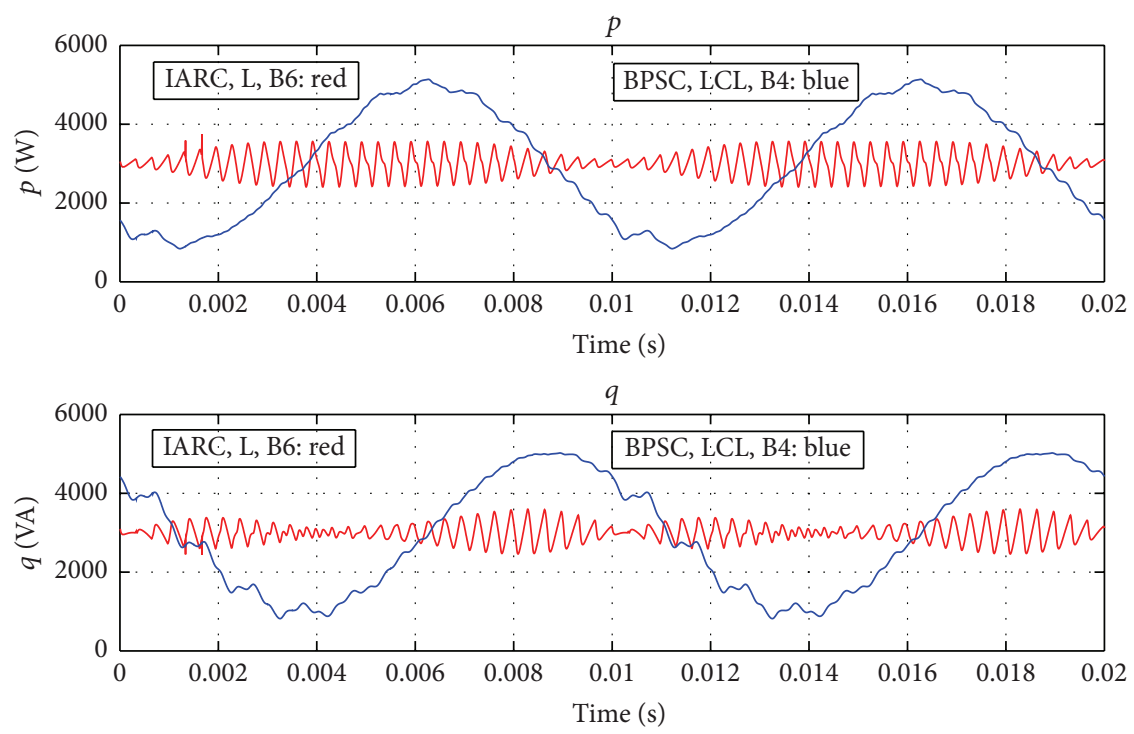

FIGURE 8: Time responses of instantaneous active and reactive powers for IARC ( $L$ filter) and BPSC ( $L C L$ filter) method. The proposed optimized half a period symmetry (B4 and B6 connection) is used.

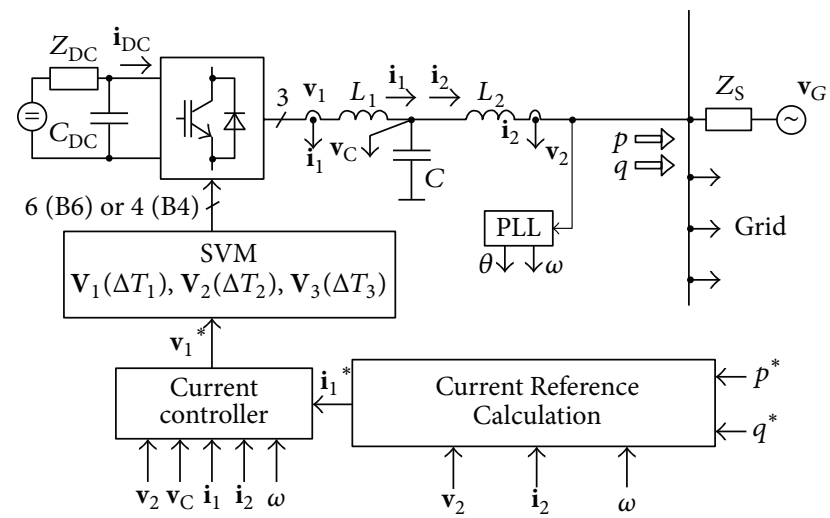

FIGURE 9: Schematic diagram of control of grid connected converter.
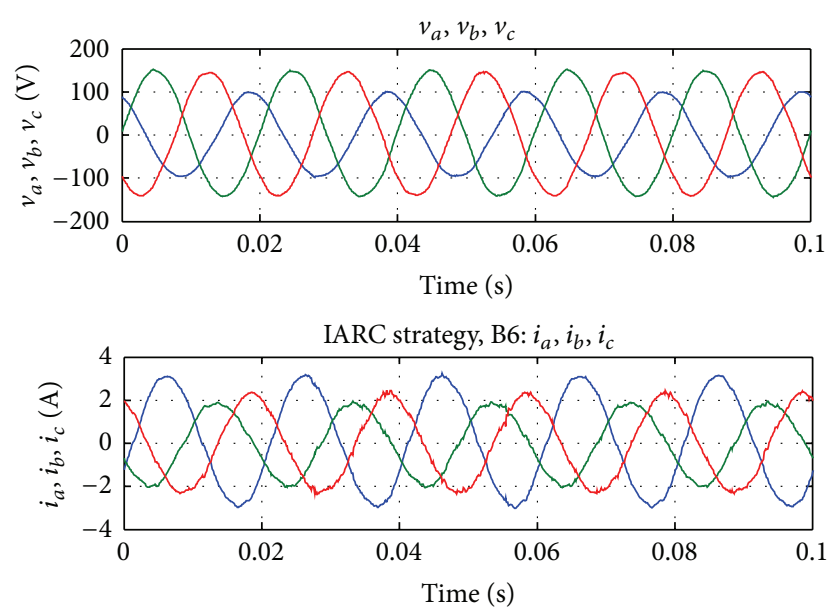

FIGURE 10: Captured trajectories of grid phase voltages and currents for the proposed IARC strategy and optimized half a period symmetry, B6 converter and LCL grid filter. conditions. The current positive and negative sequences during grid voltage sags are controlled to ensure a proper exchange of active and reactive powers without power ripples. An analytical solution of current responses in a closed form of the B6 and B4 grid connected converters working with an optimized half a period switching symmetry is presented. The analytical solution may be applied for the converters connected to highly unbalanced grids and for different grid filter topologies. The analytical closedform solution can make dimensioning of such a converter easier as well as enabling an effective choice of a grid filter topology and its parameters under nonstandard grid conditions.

\section{Appendices}

\section{A. Transfer Functions of ac Side of PWM Converter (Figure 2)}

It holds for the $L C L$ filter that

$$
\begin{aligned}
& \mathbf{v}_{S}(s)=\left(R_{1}+p L_{1}\right) \mathbf{i}_{S}(s)+\mathbf{v}_{C}(s), \\
& \mathbf{v}_{C}(s)=\left(R_{2}+p L_{2}\right)\left(\mathbf{i}_{S}(s)-\mathbf{i}_{C}(s)\right)+\mathbf{v}_{C O}(s), \\
& \mathbf{v}_{C}(s)=\frac{1}{p C} \mathbf{i}_{C}(s)+R \mathbf{i}_{C}(s),
\end{aligned}
$$

where $R$ is a damping resistor connected in series with $C$, which is not depicted in Figure 2.

After some manipulation we get the expressions for the currents $\mathbf{i}_{S}(s), \mathbf{i}_{\mathrm{CO}}(s)(21),(22)$, where

$$
\begin{aligned}
& \mathbf{B}_{S}(s)=L_{2} C s^{2}+\left(R_{2}+R\right) C s+1, \\
& \mathbf{B}_{S C O}(s)=L_{1} C s^{2}+\left(R_{1}+R\right) C s+1, \\
& \mathbf{B}_{\mathrm{CO}}(s)=R C s+1,
\end{aligned}
$$



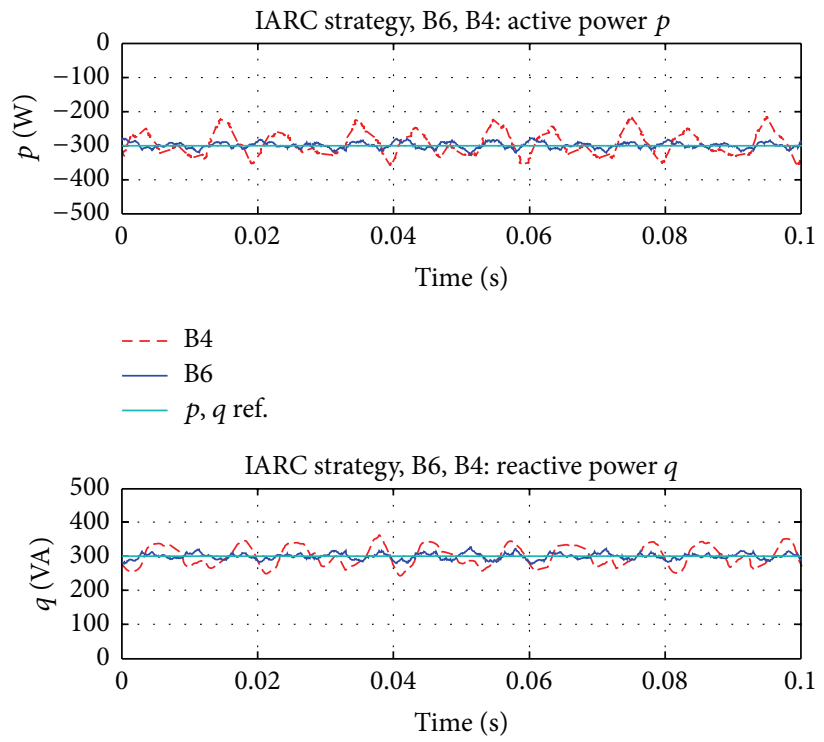

$$
\begin{aligned}
& --\mathrm{B} 4 \\
& -\mathrm{B} 6 \\
& -p, q \text { ref. }
\end{aligned}
$$

FIGURE 11: Trajectories of instantaneous active and reactive power calculated from measured converter voltages and currents for the proposed IARC strategy and optimized half a period symmetry, B6 and B4 converter and LCL grid filter.

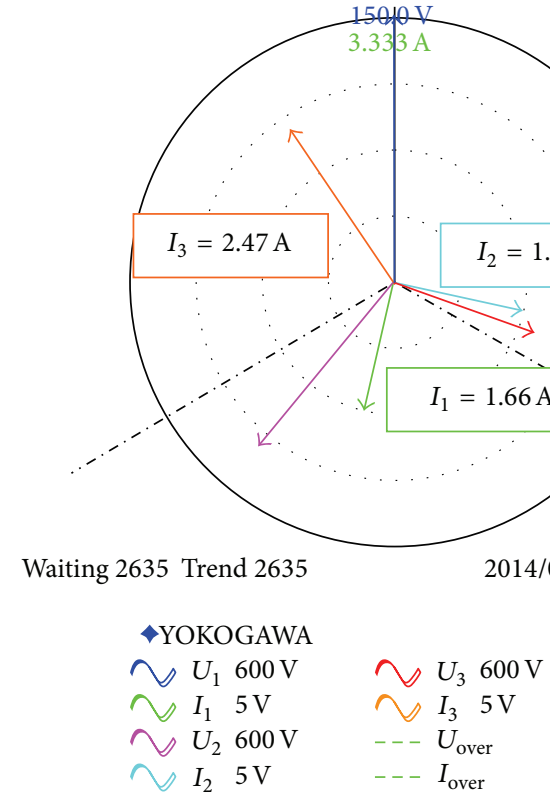

(a)

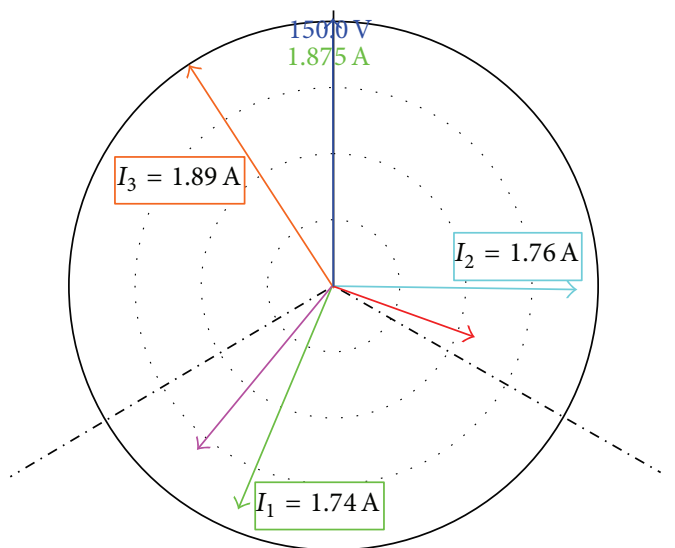

Update 10655 Trend 10655
2014/04/03 14:45:16

and cl

FIGURE 12: Measured converter voltage and current vectors for (a) IARC method, (b) BPSC strategy. The same optimized half a period symmetry; B4 converter and LCL grid filter are considered.

$\mathbf{A}(s)$

$$
\begin{aligned}
= & L_{1} L_{2} C s^{3} \\
& +\left[R C\left(L_{1}+L_{2}\right)+C\left(R_{1} L_{2}+R_{2} L_{1}\right)\right] s^{2} \\
& +\left[\left(L_{1}+L_{2}\right)+R C\left(R_{1}+R_{2}\right)+R_{1} R_{2} C\right] s \\
& +\left(R_{1}+R_{2}\right),
\end{aligned}
$$

$\mathbf{A}^{\prime}(s)$

$$
\begin{aligned}
= & 3 L_{1} L_{2} C s^{2} \\
& +2\left[R C\left(L_{1}+L_{2}\right)+C\left(R_{1} L_{2}+R_{2} L_{1}\right)\right] s \\
& +\left[\left(L_{1}+L_{2}\right)+R C\left(R_{1}+R_{2}\right)+R_{1} R_{2} C\right] .
\end{aligned}
$$



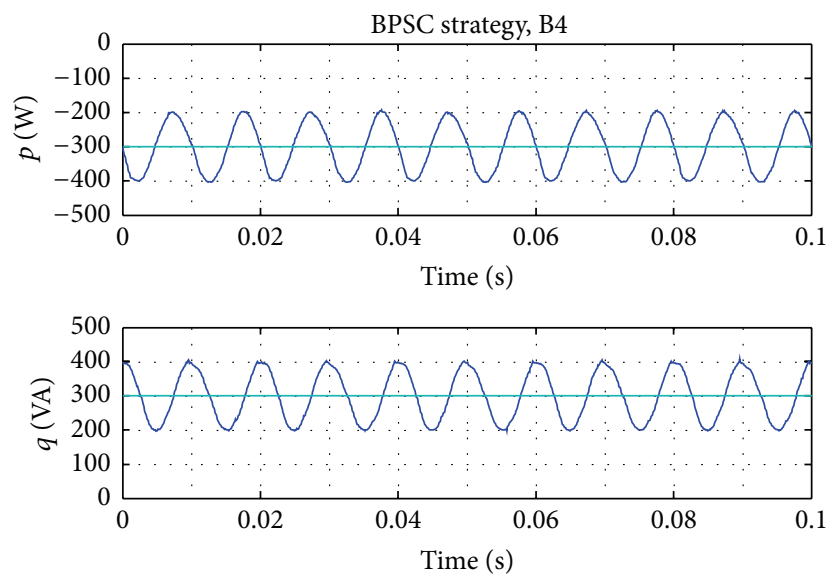

FIGURE 13: Trajectories of instantaneous active and reactive power calculated from measured converter voltages and currents for BPSC strategy, the proposed optimized half a period symmetry, B4 converter and $L C L$ grid filter.

These polynomials are used in the final expressions (B.1), (B.2).

\section{B. Closed-Form Expression for $\mathrm{i}_{S}$ in Steady States}

(1) B6 Converter. Consider

$$
\begin{aligned}
& \mathbf{i}_{S}\left(n, n_{s}, \varepsilon\right)=\mathbf{i}_{S S}\left(n, n_{s}, \varepsilon\right)+\mathbf{i}_{S C O}\left(n, n_{s}, \varepsilon\right)=\frac{\mathbf{B}_{S}\left(j \omega_{1}\right)}{\mathbf{A}\left(j \omega_{1}\right)} V_{S P} e^{j \varphi_{P}} e^{j \omega_{1}(n+\varepsilon) T}+\frac{\mathbf{B}_{S}\left(-j \omega_{1}\right)}{\mathbf{A}\left(-j \omega_{1}\right)} V_{S N} e^{j \varphi_{N}} e^{-j \omega_{1}(n+\varepsilon) T} \\
& \quad-\sum_{k=1}^{3 N_{1}}\left\{\left[\frac{\mathbf{B}_{\mathrm{CO}}(0)}{\mathbf{A}(0)} \frac{\left(e^{-j \pi m_{k}}-e^{-j \pi n_{k}}\right)}{\left(e^{j \pi}-1\right)}+\sum_{i=1}^{3} \frac{\mathbf{B}_{\mathrm{CO}}\left(s_{i}\right)}{s_{i} \mathbf{A}^{\prime}\left(s_{i}\right)} \frac{\left(e^{-j \pi m_{k}+s_{i} T\left(m_{k}-\varepsilon_{A k}\right)}-e^{-j \pi n_{k}+s_{i} T\left(n_{k}-\varepsilon_{\mathrm{Bk} k}\right)}\right)}{\left(e^{j \pi}-e^{s_{i} T}\right)} e^{s_{i} T \varepsilon}\right] \frac{2 V_{\mathrm{dc}}}{3} e^{j \pi(n+1)} e^{j(\pi / 3) \alpha(k)} e^{j \pi\left(n_{s} / 3\right)}\right\} .
\end{aligned}
$$

(2) B4 Converter. Consider

$$
\begin{aligned}
\mathbf{i}(n, \varepsilon) & =\frac{\mathbf{B}_{S}\left(j \omega_{1}\right)}{\mathbf{A}\left(j \omega_{1}\right)} V_{S P} e^{j \varphi_{P}} e^{j \omega_{1}(n+\varepsilon) T}+\frac{\mathbf{B}_{S}\left(-j \omega_{1}\right)}{\mathbf{A}\left(-j \omega_{1}\right)} \\
\cdot & V_{S N} e^{j \varphi_{N}} e^{-j \omega_{1}(n+\varepsilon) T}+\sum_{k=1}^{3 N_{1}} \frac{\mathbf{B}_{\mathrm{CO}}(0)}{\mathbf{A}(0)} V_{\mathrm{dc}} \\
& \cdot \frac{(1+\sqrt{3})}{6} e^{j n \pi} e^{j(\pi / 2) \alpha(k)} \frac{\left(e^{-j \pi m_{k}}-e^{-j \pi n_{k}}\right)}{\left(e^{j \pi}-1\right)} \\
+ & \frac{3 N_{1}}{\sum_{k=1}} \frac{\mathbf{B}_{\mathrm{CO}}(0)}{\mathbf{A}(0)} V_{\mathrm{dc}} \frac{(1-\sqrt{3})}{6} e^{-j n \pi} e^{-j(\pi / 2) \alpha(k)} \\
& \cdot \frac{\left(e^{j \pi m_{k}}-e^{j \pi n_{k}}\right)}{\left(e^{-j \pi}-1\right)}+\sum_{k=1}^{3 N_{1}} \sum_{i=1}^{3} \frac{\mathbf{B}_{\mathrm{CO}}\left(s_{i}\right)}{s_{i} \mathbf{A}^{\prime}\left(s_{i}\right)} V_{\mathrm{dc}} \\
& \cdot \frac{(1+\sqrt{3})}{6} e^{j n \pi} e^{j(\pi / 2) \alpha(k)} \\
& \cdot \frac{\left(e^{-j \pi m_{k}+s_{i} T\left(m_{k}-\varepsilon_{\mathrm{A} k}\right)}-e^{-j \pi n_{k}+s_{i} T\left(n_{k}-\varepsilon_{\mathrm{B} k}\right)}\right)}{\left(e^{j \pi}-e^{s_{i} T}\right)} e^{s_{i} T \varepsilon}
\end{aligned}
$$

$$
\begin{aligned}
& +\sum_{k=1}^{3 N_{1}} \sum_{i=1}^{3} \frac{\mathbf{B}_{\mathrm{CO}}\left(s_{i}\right)}{s_{i} \mathbf{A}^{\prime}\left(s_{i}\right)} V_{\mathrm{dc}} \frac{(1-\sqrt{3})}{6} e^{-j n \pi} e^{-j(\pi / 2) \alpha(k)} \\
& \cdot \frac{\left(e^{j \pi m_{k}+s_{i} T\left(m_{k}-\varepsilon_{\mathrm{A} k}\right)}-e^{j \pi n_{k}+s_{i} T\left(n_{k}-\varepsilon_{\mathrm{B} k}\right)}\right)}{\left(e^{-j \pi}-e^{s_{i} T}\right)} e^{s_{i} T \varepsilon},
\end{aligned}
$$

where for

prepulse per unit time $0 \leq \varepsilon<\varepsilon_{\mathrm{A} k}$

$$
m_{k}=n_{k}=1
$$

inside-pulse per unit time $\varepsilon_{\mathbf{A} k} \leq \varepsilon<\varepsilon_{\mathbf{B} k}$

$$
\begin{gathered}
m_{k}=0, \\
n_{k}=1,
\end{gathered}
$$

postpulse per unit time $\varepsilon_{\mathrm{B} k} \leq \varepsilon<1$

$$
m_{k}=n_{k}=0 .
$$

It is evident that the converter current $\mathbf{i}_{\mathrm{CO}}$ may be found easily by using the polynomials $\mathbf{B}_{\mathrm{CO}}, \mathbf{B}_{S \mathrm{SO}}$, and $\mathbf{A}$ (A.2) instead of those used in (B.1), (B.2). Also for other types of the grid filter only the polynomials (A.2) valid for the $L C L$ filter must be reformulated accordingly and then the same formulas (B.1), (B.2) may be used. 


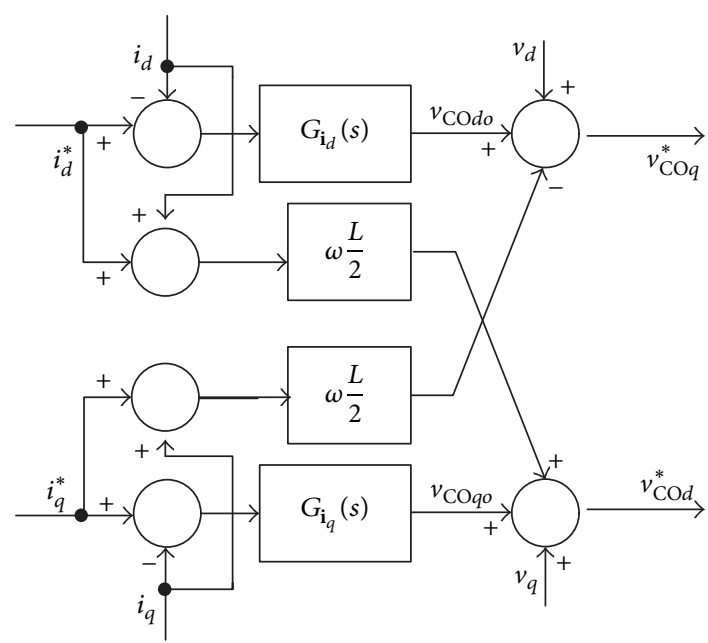

FIGURE 14: Block diagram of one-loop converter current control.

\section{Reference Current Components in the SRF and Current Control}

We can express vector equation (6) through components in $d, q$ axes of the $\operatorname{SRF}^{\mathrm{P}}$ (the upper index $\mathrm{p}$ will be omitted in the following):

$$
\begin{aligned}
\mathbf{i} & =\frac{2}{3} \frac{j}{\operatorname{Im}\left\{\mathbf{v}^{\prime *} \mathbf{v}\right\}}\left(p \mathbf{v}^{\prime}-q \mathbf{v}\right)=\left(i_{d}+j i_{q}\right) \\
& =\frac{2 / 3}{\left(v_{d}^{\prime} v_{q}-v_{q}^{\prime} v_{d}\right)}\left[p\left(-v_{q}^{\prime}+j v_{d}^{\prime}\right)-q\left(-v_{q}+j v_{d}\right)\right],
\end{aligned}
$$

where the standard transformation of the coordinates (from $a, b, c$ to $d, q$ system) conserving voltage and current magnitudes is implemented according to the following equations:

$$
\begin{aligned}
& {\left[\begin{array}{l}
x_{d} \\
x_{q}
\end{array}\right]=\frac{2}{3}} \\
& \cdot\left[\begin{array}{ccc}
\cos \theta & \cos \left(\theta-\frac{2 \pi}{3}\right) & \cos \left(\theta+\frac{2 \pi}{3}\right) \\
-\sin \theta & -\sin \left(\theta-\frac{2 \pi}{3}\right) & -\sin \left(\theta+\frac{2 \pi}{3}\right)
\end{array}\right]\left[\begin{array}{l}
x_{a} \\
x_{b} \\
x_{c}
\end{array}\right] .
\end{aligned}
$$

Thus, the current reference components are

$$
\begin{aligned}
& i_{d r}=\frac{2 / 3}{\left(v_{d}^{\prime} v_{q}-v_{q}^{\prime} v_{d}\right)}\left(-p v_{q}^{\prime}+q v_{q}\right), \\
& i_{q r}=\frac{2 / 3}{\left(v_{d}^{\prime} v_{q}-v_{q}^{\prime} v_{d}\right)}\left(p v_{d}^{\prime}-q v_{d}\right) .
\end{aligned}
$$

The errors between the current reference components and real current components enter the current controller working in the SRF ${ }^{\mathrm{P}}$. The voltage equation for the $L$ filter is

$$
\mathbf{v}_{\mathrm{CO}}=R \mathbf{i}+L \frac{d \mathbf{i}}{d t}+j \omega L \mathbf{i}+\mathbf{v}
$$

and the corresponding one-loop converter current control scheme in the $d, q$ axes of the $\mathrm{SRF}^{\mathrm{P}}$ is shown in Figure 14, now reference variables being marked by the asterisk *.

The reference voltage vector $\mathbf{v}_{\mathrm{CO}}{ }^{*}\left(\mathbf{v}_{1}{ }^{*}\right.$ in the general scheme in Figure 9) enters the block SVM where three appropriate voltage vectors and respective time portions allocated to these vectors are determined.

The instantaneous active and reactive power transferred between the converter and the grid are calculated using measured voltages and currents transformed again to the components in the $\mathrm{SRF}^{\mathrm{p}}$ :

$$
\begin{aligned}
& p=\frac{3}{2} \operatorname{Re}\left\{\mathbf{v i}^{*}\right\}=\frac{3}{2}\left(v_{d} i_{d}+v_{q} i_{q}\right) \\
& q=\frac{3}{2} \operatorname{Re}\left\{\mathbf{v}^{\prime} \mathbf{i}^{*}\right\}=\frac{3}{2}\left(v_{d}^{\prime} i_{d}+v_{q}^{\prime} i_{q}\right) .
\end{aligned}
$$

\section{Conflict of Interests}

The authors declare that there is no conflict of interests regarding the publication of this paper.

\section{Acknowledgments}

The financial supports of the Institute of Thermomechanics (Project RVO//:61388998) and SGS14/188/OHK3/3T/13 of the Czech Technical University in Prague are highly acknowledged.

\section{References}

[1] N. Pogaku, M. Prodanovic, and T. C. Green, "Modeling, analysis and testing of autonomous operation of an inverter-based microgrid," IEEE Transactions on Power Electronics, vol. 22, no. 2, pp. 613-625, 2007.

[2] S. Chakraborty, B. Kramer, and B. Kroposki, "A review of power electronics interfaces for distributed energy systems towards achieving low-cost modular design," Renewable and Sustainable Energy Reviews, vol. 13, no. 9, pp. 2323-2335, 2009.

[3] P. Rodriguez, A. V. Timbus, R. Teodorescu, M. Liserre, and F. Blaabjerg, "Flexible active power control of distributed power generation systems during grid faults," IEEE Transactions on Industrial Electronics, vol. 54, no. 5, pp. 2583-2592, 2007.

[4] R. Teodorescu, M. Liserre, and P. Rodrigues, Grid Converters for Photovoltaic and Wind Power Systems, Wiley-IEEE Press, 2011.

[5] M. Castilla, J. Miret, J. L. Sosa, J. Matas, and L. G. D. Vicuña, "Grid-fault control scheme for three-phase photovoltaic inverters with adjustable power quality characteristics," IEEE Transactions on Power Electronics, vol. 25, no. 12, pp. 2930-2940, 2010.

[6] J. Miret, M. Castilla, A. Camacho, L. G. de Vicuña, and J. Matas, "Control scheme for photovoltaic three-phase inverters to minimize peak currents during unbalanced grid-voltage sags," IEEE Transactions on Power Electronics, vol. 27, no. 10, pp. 4262-4271, 2012.

[7] A. Camacho, M. Castilla, J. Miret, J. C. Vasquez, and E. Alarcon-Gallo, "Flexible voltage support control for threephase distributed generation inverters under grid fault," IEEE Transactions on Industrial Electronics, vol. 60, no. 4, pp. 14291441, 2013. 
[8] F. Z. Peng and J.-S. Lai, "Generalized instantaneous reactive power theory for three-phase power systems," IEEE Transactions on Instrumentation and Measurement, vol. 45, no. 1, pp. 293-297, 1996.

[9] H. W. van der Broeck and J. D. van Wyk, "A comparative investigation of a three-phase induction machine drive with a component minimized voltage-fed inverter under different control options," IEEE Transactions on Industry Applications, vol. 20, no. 2, pp. 309-320, 1984.

[10] M. B. de Rossiter Corrêa, C. B. Jacobina, E. R. C. da Silva, and A. M. N. Lima, "A general PWM strategy for four-switch threephase inverters," IEEE Transactions on Power Electronics, vol. 21, no. 6, pp. 1618-1627, 2006.

[11] S. Dasgupta, S. N. Mohan, S. K. Sahoo, and S. K. Panda, "Application of four-switch-based three-phase grid-connected inverter to connect renewable energy source to a generalized unbalanced microgrid system," IEEE Transactions on Industrial Electronics, vol. 60, no. 3, pp. 1204-1215, 2013.

[12] Y. Komatsu and T. Kawabata, "A control method of active power filter in unsymmetrical voltage system," in Proceedings of the 6th European Conference on Power Electronics and Applications (EPE '95), pp. 1-904-1-907, Seville, Spain, September 1995.

[13] Y. Suh and T. A. Lipo, "A control scheme of improved transient response for PWM AC/DC converter under generalized unbalanced operating conditions," in Proceedings of the IEEE 35th Annual Power Electronics Specialists Conference (PESC '04), pp. 189-195, June 2004.

[14] W. le Roux and J. D. van Wyk, "Evaluation of residual network distortion during compensation according to the instantaneous power theory," European Transactions on Electrical Power, vol. 8, no. 5, pp. 337-343, 1998.

[15] H. W. van der Broeck, H.-Ch. Skudelny, and G. V. Stanke, "Analysis and realization of a pulsewidth modulator based on voltage space vectors," IEEE Transactions on Industry Applications, vol. 24, no. 1, pp. 142-150, 1988.

[16] J. Klima, "Time and frequency domain analysis of faulttolerant space vector PWM VSI-fed induction motor drive," IEE Proceedings-Electric Power Applications, vol. 152, no. 4, pp. 765-774, 2005.

[17] C. Klumpner, M. Liserre, and F. Blaabjerg, "Improved control of an active-front-end adjustable speed drive with a small delink capacitor under real grid conditions," in Proceedings of the 35th IEEE Annual Power Electronics Specialists Conference (PESC '04), vol. 2, pp. 1156-1162, IEEE, Aachen, Germany, June 2004. 


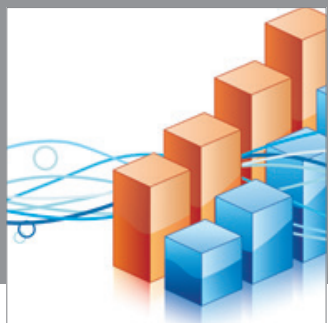

Advances in

Operations Research

mansans

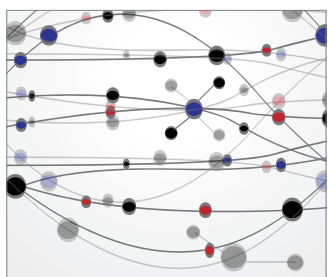

The Scientific World Journal
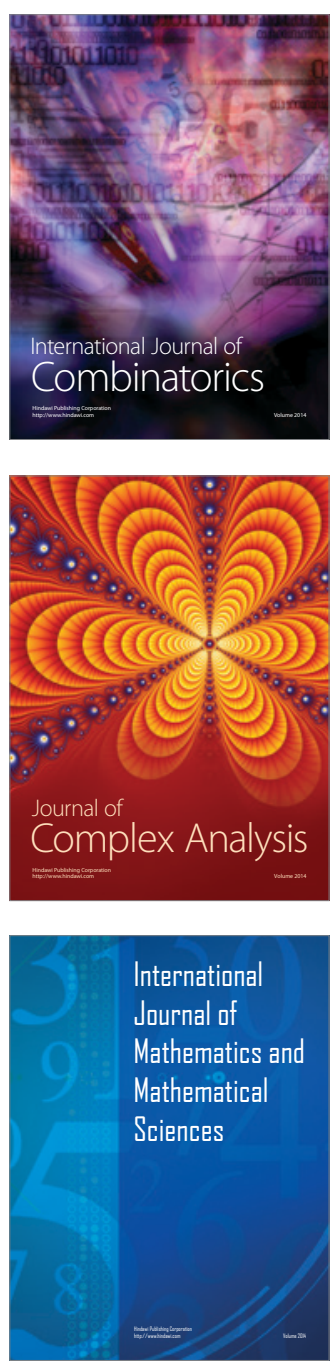
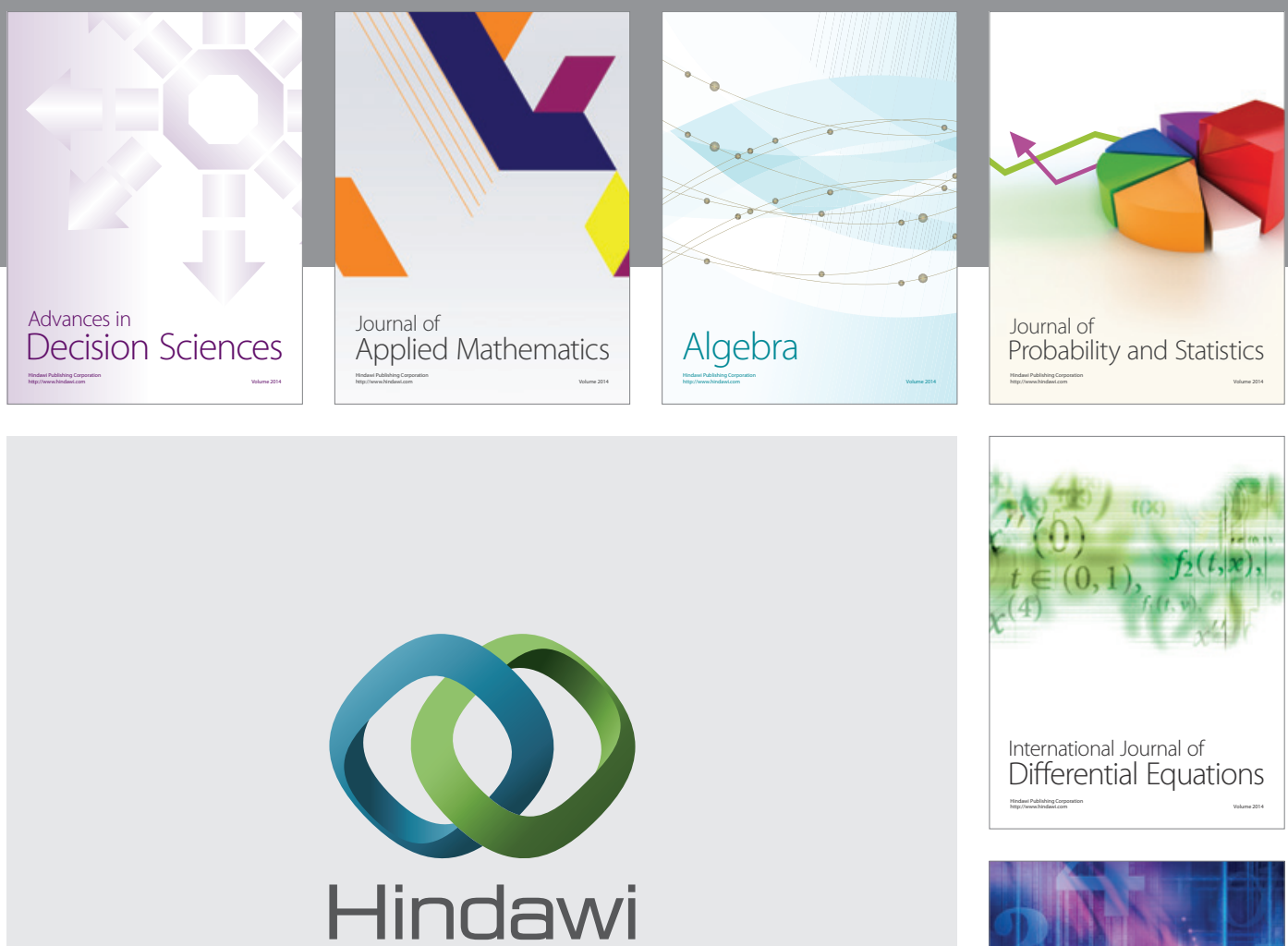

Submit your manuscripts at http://www.hindawi.com
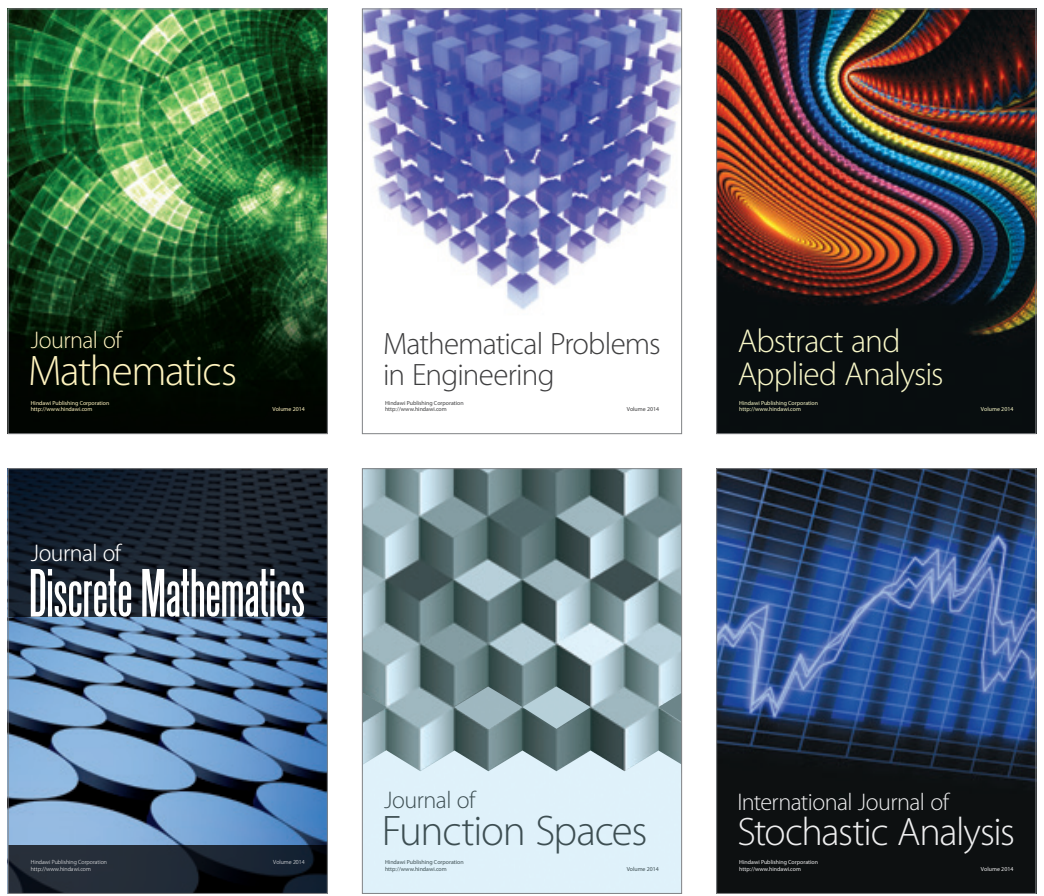

Journal of

Function Spaces

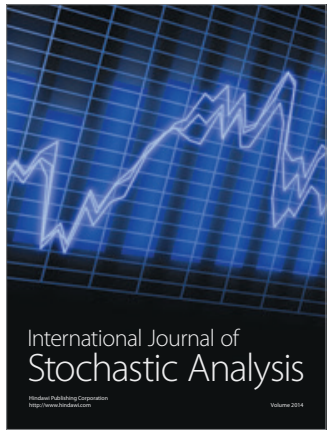

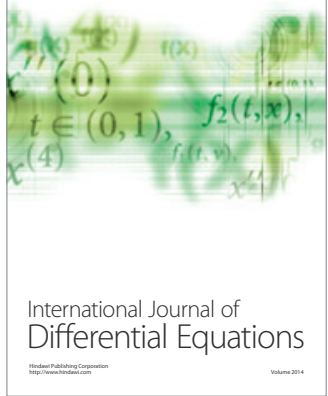
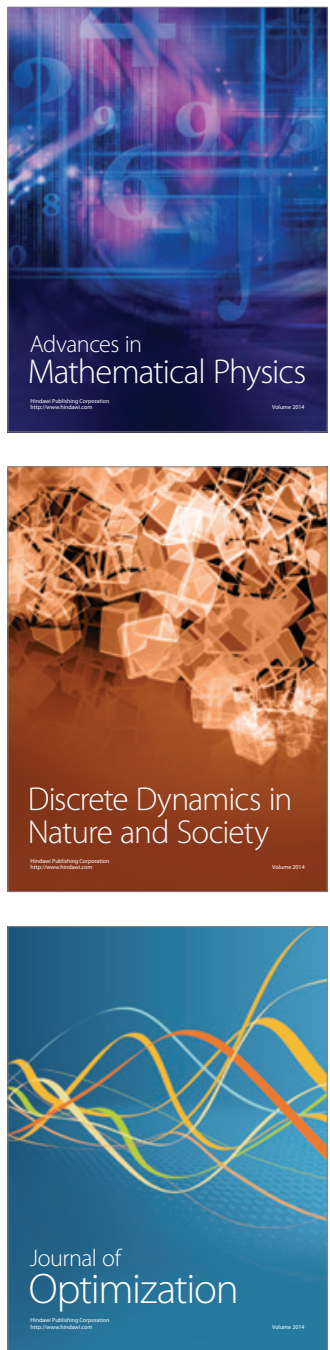